Agro-Science Journal of Tropical Agriculture, Food, Environment and Extension Volume 15 Number 2 May 2016 pp. $29-40$

ISSN 1119-7455

\title{
GROWTH, ASSIMILATE PARTITIONING AND GRAIN YIELD RESPONSE OF SOYBEAN (Glycine max L. Merrrill) VARIETIES TO CARBON DIOXIDE ENRICHMENT AND ARBUSCULAR MYCORRHIZAL FUNGI IN THE HUMID RAINFOREST
}

\author{
Sakariyawo*, O.S., Adeyemi, O.N., Atayese, M.O., and Aderibigbe, S.G. \\ Department of Plant Physiology \& Crop Production, College of Plant Science \& Crop Production, \\ Federal University of Agriculture, Abeokuta, P.M.B. 2240, Alabata, Ogun State, Nigeria \\ *Corresponding author's email: adetanwa@yahoo.co.uk
}

\begin{abstract}
This investigation tested variation in the growth components, assimilate partitioning and grain yield of soybean (Glycine max L. Merrrill) varieties established in $\mathrm{CO}_{2}$ enriched atmosphere when inoculated with mixtures of Arbuscular mycorrhizal fungi (AMF) species in the humid rainforest of Nigeria. A pot and a field experiment were established in Abeokuta $\left(7^{\circ} 15^{\prime} \mathrm{N}, 3^{\circ} 28^{\prime} \mathrm{E} ; 75 \mathrm{~m}\right.$ asl), Nigeria in 2015. The pot experiment had $\mathrm{CO}_{2}$ concentration, AMF inoculation and soybean varieties as treatments, in completely randomised design, repeated three times. On the field the treatments were in a split split-plot arrangement fitted into randomised complete block design. The main plot had $\mathrm{CO}_{2}$ concentration [ambient $(\approx 385 \mathrm{ppm})$ and elevated $\left.(\approx 550 \mathrm{ppm})\right]$, AMF inoculation in the sub plot (+AMF and $-A M F)$, while the sub sub-plot were soybean varieties $(T G x$ 1448-2E, TGx 1440-1E and TGx 1740-2F), replicated three times. In both experiments assimilatory surface increased in $\mathrm{CO}_{2}$ enriched atmosphere, with increased relative growth rate. The increased relative growth rate on the field was with increased leaf relative growth rate, reduced leaf area ratio and increased net assimilatory rate. Both trials had higher grain yield at elevated $\mathrm{CO}_{2}$ than the ambient. Growth response to AMF inoculation was with reduced specific leaf area and increased leaf weight ratio. Soybean variety TGx $1448-2 E$ was more adaptive to variation in AMF inoculation and $\mathrm{CO}_{2}$ enrichment. Soybean TGx 1740-2F was more responsive to combined effect of AMF inoculation and $\mathrm{CO}_{2}$ enrichment, but less suitable in the absence of both in this ecology.
\end{abstract}

Key words: Assimilatory surface, carbon dioxide enrichment, inoculation, soybean

\section{INTRODUCTION}

Soybean is an important oil seed crop in most parts of the world. In Nigeria, its cultivation is on the rise in most agroecological systems (Obalum et al., 2011). Its agronomic importance is premised on its ability to biologically fix atmospheric nitrogen; hence it forms an important component of the cropping system apart from its nutritional value (Harold et al., 1990).

Global attention in recent past has shifted to the implications of climate change, specifically for crop growth (Poorter, 1993) and agricultural productivity (Cure and Acock, 1986). Elevation of atmospheric carbon dioxide concentration had been reported to be part of this global climate change (Leakey et al., 2009). Though the carbon foot print of most developing and underdeveloped regions is low compared to the developed world, there is need to establish a proactive measure against the negative impact of climate change in these regions. The need is underlined by the fact that these regions are characterized by low input agriculture, low soil fertility (Uzoh et al., 2015), rainfed and subsistence in nature. This farming system is unsustainable in the long run due partly to changes in their demographic profiles (Idris et al., 2013). It had been reported in the literature that there is interspecific variation on growth in $\mathrm{CO}_{2}$ enriched atmosphere (Poorter, 1993). Crops with C3 carbon assimilation were observed to benefit more under elevated $\mathrm{CO}_{2}$ than $\mathrm{C} 4$, especially when other growth factors are non-limiting (Poorter, 1993). However, the $\mathrm{C} 4$ plants could benefit in $\mathrm{CO}_{2}$ enriched atmosphere under drought condition (Leakey et al., 2009). Among the $\mathrm{C} 3$ it was reported that leguminous crop could benefit more in $\mathrm{CO}_{2}$ enriched atmosphere than non-leguminous crops (Poorter, 1993). The underlying mechanism for this was reported by (Aranjuelo et al., 2014). Other variations observed among the $C 3$ under elevated $\mathrm{CO}_{2}$ was between dicotyledonous and monocotyledonous crops, with the former indicating better performance than the later (Poorter, 1993). 
Soybean crop exhibits different growth habits; determinate and indeterminate. There have been reports in the literature on the effect of varietal differences on growth of soybean with different growth habits under elevated atmospheric $\mathrm{CO}_{2}$ (Dornhoff and Shibles, 1970). It is still unknown the effect of $\mathrm{CO}_{2}$ enriched atmosphere on the growth components of soybean varieties in the humid tropics.

The effect of symbiotic association of crops with arbuscular mycorrhizal fungi is well reported in the literature (Augé, 2004; Kaschuk et al., 2009; Smith and Read, 2008; Wu and Zou, 2010). It was reported that in combination with $\mathrm{N}$-fixing symbionts there could be increased metabolic sink towards improved canopy photosynthesis (Kaschuk et al., 2009). Meghvansi et al., (2008) reported that the response of soybean cultivar to inoculation with three arbuscular mycorrhizal in combination with Bradyrhizobium japonicum varies with the specie of arbuscular mycorrhizal fungi involved. There is no documented evidence on the effect of Arbuscular Mycorrhizal Fungi (AMF) mixture on the performance of soybean in the humid tropical region to the best of our knowledge. Furthermore few studies have been conducted on the combined effect of symbionts on growth components of soybean under elevated $\mathrm{CO}_{2}$ condition.

This investigation tested the hypothesis that there would be variation in the growth components of soybean varieties established in $\mathrm{CO}_{2}$ enriched atmosphere under the combined effects of symbionts in the humid rainforest. Understanding of this process would have an impact on the sustainable production of soybean in this agroecology. The objective of this trial was to evaluate variation on the growth, growth components, assimilate partitioning and grain yield of soybean varieties under elevated atmospheric $\mathrm{CO}_{2}$ with mixtures of arbuscular mycorrhizal fungi.

\section{MATERIALS AND METHODS}

Pot and field experiments were conducted at Abeokuta in the year 2015.

\section{Pot experiment}

This trial was conducted in the screen house of the College of Plant Science and Crop Production, Federal University of Agriculture, Abeokuta.

\section{Experimental Treatments and Design}

This experiment consisted of $\mathrm{CO}_{2}$ enrichment [ambient $(\approx 385 \mathrm{ppm})$ and elevated $(\approx 550 \mathrm{ppm})$ ], with soybean varieties (TGx 1448-2E, TGx 1440-1E and TGx 1740-2F) inoculated with AMF (inoculated, uninoculated). The inoculum (Empathy Mycorrhizal Rootgrow $^{\mathrm{TM}}$ Fungi) was sourced commercially. It was a mixture of different AMF species. The experiment was in completely randomised design, replicated three times.

\section{Cultural operations}

Three plastic pots were used for each treatment. A total of one hundred and eight plastic pots were used. Each pot was $25 \mathrm{~cm}$ wide at the surface and $36 \mathrm{~cm}$ deep with 10 litres capacity. The pots were perforated at the bottom to allow for easy drainage of excess water without depleting the soil quantity. The sampled soil was thoroughly mixed and sieved using $2.0 \mathrm{~mm}$ mesh sieve. Each pot was filled with $7 \mathrm{~kg}$ of sieved soil that was maintained at $100 \%$ field capacity. The pots were left for $72 \mathrm{~h}$ before planting. Soybean seeds were obtained from the International Institute of tropical Agriculture (IITA), Ibadan.

Carbon dioxide enrichment was established in an open top chamber (OTC) that was placed in the screen house. The OTC was constructed using polyvinyl chloride (PVC) pipes. These were covered with transparent PVC nylon sheet to ease the penetration of radiant energy into the chamber. The OTC was $2.5 \mathrm{~m}$ in height with an area of $12 \mathrm{~m}^{2}$. To enrich the OTC with the required concentration of carbon dioxide $12 \mathrm{CO}_{2}$ generator bottles were placed in the chamber. Carbon dioxide production in the chamber was implemented according to the protocol developed by Saitoh et al. (2004).

The maximum and minimum $\mathrm{CO}_{2}$ concentration in the OTC was measured was at 11:00 am and 4:00 pm throughout the enrichment period (4 to 9 WAP) using a portable $\mathrm{CO}_{2}$ meter [NDIR Gas Analyzer (Bentech GM8883), China]. The mean of the maximum and minimum $\mathrm{CO}_{2}$ concentration was used to determine the $\mathrm{CO}_{2}$ level in the OTC. Transparent walls of the OTC were kept clean regularly in order to minimise any differences in the light levels between inside and outside the chamber. The control pots were grown in ambient atmospheric conditions. Two grammes of AMF granules were sprinkled into the base of the planting hole at planting. This was later covered with soil with soybean seeds. Three seeds were planted at a depth of 20-30 mm in the soil and later thinned to one plant per pot two weeks after planting (WAP). The initial spore count in $2 \mathrm{~g}$ of AMF granules was determined. The pots were transferred into the chamber at 4 WAP. Water was supplied thrice in a week to irrigate the plants. Weeding was conducted manually as at when due.

\section{Sampling and data collection}

A composite soil sample was collected before planting to determine soil physical and chemical properties. The soil for the trials was collected from the same experimental field. The soil was collected from a depth of $0-30 \mathrm{~cm}$ depth. Non destructive growth variables (number of trifoliate leaves per plant and trifoliate leaf area) were determined at 3, 6 and 9 WAP in one set of pot. Total leaf area of the 
crop was calculated using the equation derived by Wiersma and Bailey (1975):

$$
\mathrm{A}=0.411+2.008 \mathrm{LW}
$$

where $\mathrm{A}$ is trifoliate leaf area, and $\mathrm{L}$ and $\mathrm{W}$ are the maximum length and maximum width of the terminal leaflet of a trifoliate leaf, respectively.

Destructive sampling (mycorrhizal colonisation, AMF sporulation, dry matter accumulation and partitioning) was conducted at $6,9 \mathrm{WAP}$ and harvest maturity in the remaining two sets of pots. Grain yield per plant was determined at harvest maturity. Harvest maturity was evaluated visually when $95 \%$ of the pods had turned to brown, suggesting a reduction in the pod moisture content. Growth variables were determined using classical approach with two means values obtained at two harvest intervals of 21 days. The primary data (leaf area and dry weight) for the determination of growth components were transformed using log to base 10 .

Relative growth rate (RGR), leaf relative growth rate (LRGR), leaf area ratio (LAR), specific leaf area (SLA), specific leaf weight (SLW) and net assimilatory rates (NAR) were determined according to the methods proposed by Hunt (2012). Fractional distribution of the assimilate to different organs was also determined for the leaf and stem. The partitioned plant parts were oven dried at $70^{\circ} \mathrm{C}$ to a constant weight to determine leaf and stem weight fractions, which were the proportions of these organs to the total dry weight. Chlorophyll content was determined using SPAD chlorophyll meter.

\section{Mycorrhizal Analysis}

Root samples were collected from the pots for the determination of percentage root colonisation. Collected root samples were prepared using the method as described Phillips and Hayman (1970). Prepared root samples were rinsed off staining solution with clean tap water, cut into $1-\mathrm{cm}$ pieces. They were preserved with $40 \%$ glycerol solution for further viewing under compound microscope to determine percentage root colonisation (PCR):

$$
P C R=\frac{\text { Number of infected roots }}{\text { Total number of roots }} \times 100
$$

From the rhizosphere $20 \mathrm{~g}$ of well mixed soil samples were collected from the pot for the determination of the soil spore count before and after inoculation. Extraction of AMF spores from the soil sample was conducted using the modified wet sieving method of Giovannetti and Mosse (1980). Extracted spores were identified using digital compound microscope and counted under dissecting slides. The initial spore count in the $20 \mathrm{~g}$ of the soil was between 3-5 spores.
Field experiment

Characterisation of location and experimental site

This was carried out at the Federal University of Agriculture Abeokuta (FUNAAB), Ogun State, Nigeria. The geographical location lies in the SouthWestern Nigeria $\left(7^{\circ} 15^{\prime} \mathrm{N}, 3^{\circ} 28^{\prime} \mathrm{E}\right.$; $75 \mathrm{~m}$ asl). The particle size analysis showed that the textural class of the soil was sandy with a $\mathrm{pH}$ that was slightly acidic (6.5). It has total nitrogen of $0.8 \mathrm{mg} \mathrm{kg} \mathrm{kg}^{-1}$ and available $\mathrm{P}$ value of $5.23 \mathrm{mg} \mathrm{kg}^{-1}$ with soil organic matter of $1.12 \%$. The textural class of the site was determined using the USDA textural triangle. The collected soil sample was air-dried after collection. Soil particle size distribution was determined using the hydrometer method (Bouyoucos, 1962). The active $\mathrm{pH}$ was determined in 1:1 soil: water using a $\mathrm{pH}$ meter (glass electrode) as described by (McLean, 1982). The organic carbon content of the samples was determined using Walkey-Black method as modified by Allison et al. (1965). Total nitrogen was determined using modified micro-Kjeldahl digestion technique (Jackson, 1962). Available phosphorus was determined using Bray-1 (Bray and Kurtz, 1945) and determined colometrically using the method of Murphy and Riley, (1962). Exchangeable bases were extracted with $1 \mathrm{~N}$ ammonium acetate buffered at $\mathrm{pH}$ of 7. Sodium and $\mathrm{K}^{+}$in the extract were determined by flame photometry, $\mathrm{Ca}^{2+}$ and $\mathrm{Mg}^{2+}$ were determined using Atomic Absorption Spectrophotometer (AAS). Total acidity $\left(\mathrm{H}^{+}+\mathrm{Al}^{3+}\right)$ was determined using $\mathrm{KCl}$ as the extracting medium. Cation exchange capacity was determined by the summation of total exchangeable bases and exchangeable acidity. During the cropping season in the year 2015 the rainfall pattern was in the range of $165.1 \mathrm{~mm}$ (September)-no precipitation (December). The maximum temperature during the cropping season was observed in November and December $\left(33.5^{\circ} \mathrm{C}\right)$, while the minimum was recorded in August $\left(29.5^{\circ} \mathrm{C}\right)$ (Fig. 1).

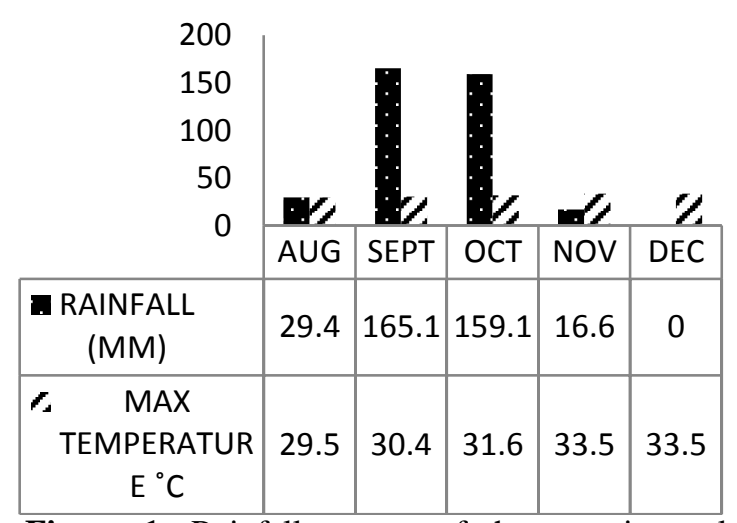

Figure 1: Rainfall pattern of the experimental location during 2015 cropping season 


\section{Experimental Treatments and Design}

The field experiment had similar treatments with the pot trial. The treatments were arranged in split splitplot with $\mathrm{CO}_{2}$ concentration [ambient $(\approx 385 \mathrm{ppm})$ and elevated $(\approx 550 \mathrm{ppm})]$ in the main plot, $\mathrm{AMF}$ inoculation in the subplot (+ AMF and - AMF), while the sub-sub-plot consisted of soybean variety (TGx 1448-2E, TGx 1440-1E and TGx 1740-2F). AMF inoculation had similar source as that in the pot trial. This arrangement was fitted into randomised complete blocked design, replicated three times.

\section{Cultural operations}

The initial spore count of the soil used was determined prior to field establishment. The field was ploughed twice and disc-harrowed once two weeks later for proper field establishment. The gross plot size measured $2 \times 2 \mathrm{~m}\left(4 \mathrm{~m}^{2}\right)$ and net plot size was $1.5 \times 1.5 \mathrm{~m}\left(2.25 \mathrm{~m}^{2}\right)$. The space between plots was $0.5 \mathrm{~m}$, while between replicates was $1 \mathrm{~m}$. Three seeds of soybean were planted per hole at a depth of $2-5 \mathrm{~cm}$ and at a spacing of $50 \times 10 \mathrm{~cm}$ on $10^{\text {th }}$ of August 2015. It was later thinned to one plant per stand two weeks after planting (WAP). This translated to five rows per plot, with each row consisting of 21 plants. The plant density was 105 plants per plot. Treated plots were inoculated with AMF inoculums during planting. The planting hole was sprinkled with $25 \mathrm{~g}$ of commercially sourced inoculums, which was covered with soil. On $\mathrm{CO}_{2}$ enriched plots soybean seeds were established in OTC that measured $2 \mathrm{~m}$ height and area of $31.5 \mathrm{~m}^{2}$. They were installed on the plots at 4WAP. They were made of the same materials as those constructed for the screen house. Generation of $\mathrm{CO}_{2}$, its monitoring and enrichment period was as described for the screen house trial. Weeding was done manually at 3,6 and 9 WAP.

\section{Sampling and data collection}

Five plants from the net plot were randomly chosen for the determination of growth variables. Destructive sampling was conducted from the rows outside the net plot aside from the two rows bordering the gross plot. The growth variables were the same as those determined in the screen house except Leaf Area Index on the 3, 6 and 9 WAP. Leaf area index (LAI) was determined as the ratio of leaf area to unit land area occupied by the plant. Growth analysis followed the classical approach as described for the screen house trial. Mycorrhizal colonisation, spore count, dry matter accumulation and factional distribution of the assimilates followed similar protocol as in the screen house. Grain yield per hectare was determined at harvest maturity as earlier described and was extrapolated from the net plot.

\section{Statistical analysis}

Analysis of Variance (ANOVA) using a fixed model was conducted to determine significant differences among the means at 5\% probability level. A mixed model ANOVA was conducted for the field trial. Carbon dioxide, AMF and soybean variety were the fixed factors. Discrete data were transformed using square root transformation prior to analysis. Significant means were separated using Least Significant Difference (LSD). The statistical package used was Genstat $12^{\text {th }}$ Edition.

\section{RESULTS \\ Pot Experiment}

Soybean crop exposed to elevated $\mathrm{CO}_{2}$ had significantly more number of trifoliate leaves and leaf area at 6 and 9 WAP than those exposed to ambient $\mathrm{CO}_{2}$ concentration except at $3 \mathrm{WAP}$, where there were no significant differences on the number of trifoliate leaves in soybean at different atmospheric $\mathrm{CO}_{2}$ concentration (Table 1). At all periods of investigation chlorophyll content was similar in both enriched and ambient concentration of $\mathrm{CO}_{2}$ in the atmosphere. There were no significant differences between inoculated and uninoculated soybean on the number of trifoliate leaves except at 3 WAP. Inoculated soybean had more number of trifoliate leaves than uninoculated. Similar pattern was observed on the leaf area at 3 and 6 WAP. Inoculation had no significant effect on the chlorophyll content at all periods of investigation. There were no significant varietal differences on the aforementioned growth variables during the period of investigation (Table 1).

Soybean crop exposed to $\mathrm{CO}_{2}$ enriched atmosphere had significantly higher aboveground dry weight than those exposed to ambient $\mathrm{CO}_{2}$ concentration at 9 WAP and at harvest maturity (Table 2). Inoculated soybean crop had significantly higher aboveground dry weight than uninoculated ones at all periods of investigation except 6 WAP. Soybean varieties had similar aboveground dry weight at all periods of investigation (Table 2). The $\mathrm{CO}_{2}$ enrichment had no significant effect on leaf weight ratio and stem weight ratio at all periods of investigation (Table 3). At 9 WAP more assimilates were partitioned into leaf in inoculated soybean than uninoculated. Contrarily, at 9 WAP more assimilates were partitioned into the stem in uninoculated soybean than inoculated. There were no significant varietal differences on leaf mass and stem mass ratio at all periods of investigation (Table 3). Soybean crop grown in enriched atmosphere had similar specific leaf area with those grown at ambient $\mathrm{CO}_{2}$ concentration (Table 4). Similar pattern was observed on specific leaf weight and leaf area ratio at all periods of investigation (Table 4). Uninoculated soybean crop had significantly 
Table 1: Effect of $\mathrm{CO}_{2}$ enrichment and AMF inoculation on number of trifoliolate leaves, trifoliolate leaf area and chlorophyll content of soybean cultivars at 3,6 and 9 WAS (screen house experiment)

\begin{tabular}{|c|c|c|c|c|c|c|c|c|c|}
\hline \multirow[b]{2}{*}{ Treatments } & \multicolumn{3}{|c|}{ Number of trifoliolate leaves } & \multicolumn{3}{|c|}{ Leaf area $\left(\mathrm{cm}^{2}\right)$} & \multicolumn{3}{|c|}{ Chlorophyll content } \\
\hline & 3 WAP & $6 \mathrm{WAP}$ & 9 WAP & 3 WAP & 6 WAP & 9 WAP & 3 WAP & 6WAP & 9 WAP \\
\hline \multicolumn{10}{|l|}{$\mathrm{CO}_{2}$ Level $(\mathrm{C})$} \\
\hline Ambient & 2.55 & 10.06 & 18.11 & 30.91 & 65.4 & 101.1 & 37.3 & 34.2 & 32.2 \\
\hline Elevated & 2.61 & 15.67 & 27.11 & 27.14 & 91.8 & 155.1 & 37.6 & 35.1 & 33.5 \\
\hline LSD & NS & $2.41 * *$ & $2.52 * *$ & NS & $6.8 * *$ & $17.5^{* *}$ & NS & NS & NS \\
\hline \multicolumn{10}{|l|}{$\operatorname{AMF}(\mathrm{A})$} \\
\hline Inoculated & 3.0 & 13.28 & 23.56 & 33.28 & 82.8 & 133.1 & 37.8 & 35.0 & 33.1 \\
\hline Un-inoculated & 2.17 & 12.44 & 21.67 & 24.78 & 74.4 & 123.1 & 37.11 & 34.2 & 32.7 \\
\hline LSD & $0.36^{* *}$ & NS & NS & $3.79 * *$ & $6.8^{*}$ & NS & NS & NS & NS \\
\hline \multicolumn{10}{|l|}{ Varieties (V) } \\
\hline TGx 1448-2E & 2.50 & 11.67 & 21.92 & 26.93 & 79.9 & 130.4 & 36.6 & 35.9 & 34.2 \\
\hline TGx 1440-1E & 2.58 & 14.08 & 23.75 & 30.32 & 76.2 & 129.4 & 39.7 & 34.5 & 33.5 \\
\hline TGx 1740-2F & 2.67 & 12.83 & 22.17 & 29.83 & 79.7 & 124.4 & 36.2 & 33.4 & 31.2 \\
\hline LSD & NS & NS & NS & NS & NS & NS & NS & NS & NS \\
\hline $\mathrm{C} \times \mathrm{A}$ & NS & NS & NS & NS & NS & NS & NS & NS & NS \\
\hline $\mathrm{C} \times \mathrm{V}$ & NS & NS & NS & NS & $11.8 *$ & NS & NS & NS & NS \\
\hline $\mathrm{C} \times \mathrm{A} \times \mathrm{V}$ & NS & NS & $\mathrm{NS}$ & $\mathrm{NS}$ & $16.65 *$ & NS & NS & NS & NS \\
\hline
\end{tabular}

Table 2: Effects of $\mathrm{CO}_{2}$ enrichment and AMF inoculation on aboveground dry weight of soybean cultivars at 6 and 9 WAP and harvest maturity (screen house experiment)

\begin{tabular}{lccc}
\hline & \multicolumn{3}{c}{ Aboveground dry weight $\left(\right.$ g plant $\left.^{-1}\right)$} \\
Treatments & 6 WAP & 9 WAP & Harvest maturity \\
\hline $\mathrm{CO}_{2}$ level (C) & & & \\
Ambient & 1.78 & 5.25 & 20.34 \\
Elevated & 2.22 & 8.74 & 31.27 \\
LSD & $\mathrm{NS}$ & $1.87 * *$ & $3.43^{*}$ \\
AMF (A) & 1.99 & 7.97 & 30.15 \\
Inoculated & & & \\
Un-inoculated & 2.01 & 6.03 & 21.46 \\
LSD & $\mathrm{NS}$ & $1.87 *$ & $3.43^{*}$ \\
Varieties (V) & & & \\
TGx 1448-2E & 1.86 & 6.77 & 23.10 \\
TGx 1440-1E & 2.06 & 7.14 & 27.28 \\
TGx 1740-2F & 2.08 & 7.08 & 27.03 \\
LSD & NS & NS & NS \\
C $\times$ A & NS & NS & $4.73^{* *}$ \\
C $\times$ V & NS & NS & NS \\
A $\times$ V & NS & NS & NS \\
C $\times$ A $\times$ V & NS & NS & $8.19 *$ \\
$*$ Significant at 5\% probability level; **Significant at 1\% probability level, \\
NS: not significant, WAP: weeks after planting
\end{tabular}

Table 3: Effects of $\mathrm{CO}_{2}$ enrichment and $\mathrm{AMF}$ inoculation on leaf weight ratio and stem weight ratio of soybean cultivars at 6 and 9 WAS (screen house experiment)

\begin{tabular}{lcccc}
\hline \multirow{2}{*}{ Treatments } & \multicolumn{2}{c}{ Leaf weight ratio } & \multicolumn{2}{c}{ Stem weight ratio } \\
\cline { 2 - 5 } & 6 WAP & 9 WAP & 6 WAP & 9 WAP \\
\hline $\mathrm{CO}_{2}$ level (C) & & & & \\
Ambient & 0.78 & 0.77 & 0.22 & 0.23 \\
Elevated & 0.77 & 0.76 & 0.23 & 0.24 \\
LSD & NS & NS & NS & NS \\
AMF (A) & & & & \\
Inoculated & 0.78 & 0.80 & 0.22 & 0.20 \\
Un-inoculated & 0.77 & 0.73 & 0.23 & 0.27 \\
LSD & NS & $0.065^{*}$ & NS & $0.065^{*}$ \\
Varieties (V) & & & & \\
TGx 1448-2E & 0.77 & 0.77 & 0.23 & 0.23 \\
TGx 1440-1E & 0.78 & 0.79 & 0.22 & 0.21 \\
TGx 1740-2F & 0.78 & 0.73 & 0.22 & 0.27 \\
LSD & NS & NS & NS & NS \\
C $\times$ A & NS & NS & NS & NS \\
C $\times$ V & NS & NS & NS & NS \\
A $\times$ V & NS & NS & NS & NS \\
C $\times$ A $\times$ V & NS & NS & NS & NS \\
\hline *Significant at 5\% probability level; **Significant at $1 \%$ probability level, \\
NS: Not significant, WAP: weeks after planting &
\end{tabular}

Table 4: Effects of $\mathrm{CO}_{2}$ enrichment and AMF inoculation on specific leaf area, specific leaf weight and leaf area ratio of soybean cultivars at 6 and 9 WAS (pot experiment)

\begin{tabular}{|c|c|c|c|c|c|c|}
\hline \multirow{2}{*}{ Treatments } & \multicolumn{2}{|c|}{ Specific leaf area $\left(\mathrm{cm}^{2} \mathrm{~g}^{-1}\right)$} & \multicolumn{2}{|c|}{ Specific leaf weight $\left(\mathrm{g} \mathrm{cm}^{-2}\right)$} & \multicolumn{2}{|c|}{ Leaf area ratio } \\
\hline & $6 \mathrm{WAP}$ & 9 WAP & $6 \mathrm{WAP}$ & $9 \mathrm{WAP}$ & $6 \mathrm{WAP}$ & $9 \mathrm{WAP}$ \\
\hline \multicolumn{7}{|l|}{$\mathrm{CO}_{2}$ level $(\mathrm{C})$} \\
\hline Ambient & 53.9 & 30.6 & 0.023 & 0.042 & 42.0 & 22.8 \\
\hline Elevated & 57.0 & 28.1 & 0.019 & 0.044 & 44.2 & 19.5 \\
\hline LSD & NS & NS & NS & NS & NS & NS \\
\hline \multicolumn{7}{|l|}{$\mathrm{AMF}(\mathrm{A})$} \\
\hline Inoculated & 58.5 & 23.4 & 0.019 & 0.047 & 45.9 & 18.5 \\
\hline Un-inoculated & 52.4 & 35.4 & 0.022 & 0.039 & 40.2 & 23.7 \\
\hline LSD & NS & $11.6^{*}$ & NS & NS & NS & NS \\
\hline \multicolumn{7}{|l|}{ Varieties (V) } \\
\hline TGx $1448-2 \mathrm{E}$ & 63.2 & 30.7 & 0.018 & 0.039 & 48.8 & 23.1 \\
\hline TGx $1440-1 \mathrm{E}$ & 50.0 & 26.2 & 0.023 & 0.046 & 38.9 & 19.9 \\
\hline TGx 1740-2F & 53.1 & 31.2 & 0.021 & 0.044 & 41.5 & 20.3 \\
\hline LSD & NS & NS & NS & NS & NS & NS \\
\hline $\mathrm{C} \times \mathrm{A}$ & NS & NS & NS & NS & NS & NS \\
\hline $\mathrm{C} \times \mathrm{V}$ & NS & NS & NS & NS & NS & NS \\
\hline $\mathrm{A} \times \mathrm{V}$ & NS & NS & NS & NS & NS & NS \\
\hline $\mathrm{C} \times \mathrm{A} \times \mathrm{V}$ & NS & NS & NS & NS & NS & NS \\
\hline
\end{tabular}

*Significant at $5 \%$ probability level; **Significant at $1 \%$ probability level, NS: Not significant, WAP: weeks after planting 
Table 5: Effects of $\mathrm{CO}_{2}$ enrichment and $\mathrm{AMF}$ inoculation on relative leaf growth rate, relative growth rate, net assimilatory ratio and grain yield of soybean cultivars (pot experiment)

\begin{tabular}{|c|c|c|c|c|}
\hline \multirow{3}{*}{ Treatments } & $\begin{array}{l}\text { Leaf } \\
\text { relative } \\
\text { growth } \\
\text { rate }\end{array}$ & $\begin{array}{l}\text { Relative } \\
\text { growth } \\
\text { rate }\end{array}$ & \multirow[t]{2}{*}{$\begin{array}{l}\text { Net } \\
\text { assimi- } \\
\text { latory } \\
\text { ratio }\end{array}$} & \multirow[t]{2}{*}{$\begin{array}{c}\text { Grain } \\
\text { yield } \\
\left(\mathrm{g}^{2} \text { plant }\right. \\
\end{array}$} \\
\hline & \multicolumn{2}{|c|}{$\left(\mathrm{g} \mathrm{g}^{-1}\right.$ day $\left.^{-1}\right)$} & & \\
\hline & R2 & R2 & R2 & $\begin{array}{l}\text { Harvest } \\
\text { maturity }\end{array}$ \\
\hline \multicolumn{5}{|l|}{$\mathrm{CO}_{2}$ level $(\mathrm{C})$} \\
\hline Ambient & 0.048 & 0.049 & 0.0021 & 7.27 \\
\hline Elevated & 0.062 & 0.064 & 0.0026 & 10.68 \\
\hline LSD & NS & $0.012 *$ & NS & $1.03 * *$ \\
\hline \multicolumn{5}{|l|}{$\mathrm{AMF}(\mathrm{A})$} \\
\hline Inoculated & 0.065 & 0.064 & 0.0026 & 9.31 \\
\hline Un-inoculated & 0.046 & 0.050 & 0.0021 & 8.64 \\
\hline LSD & $0.014 *$ & $0.012 *$ & NS & NS \\
\hline \multicolumn{5}{|l|}{ Varieties (V) } \\
\hline TGx $1448-2 \mathrm{E}$ & 0.058 & 0.058 & 0.0021 & 9.90 \\
\hline TGx 1440-1E & 0.058 & 0.058 & 0.0025 & 8.31 \\
\hline TGx 1740-2F & 0.050 & 0.054 & 0.0024 & 8.71 \\
\hline LSD & NS & NS & NS & $1.26^{*}$ \\
\hline $\mathrm{C} \times \mathrm{A}$ & NS & NS & NS & NS \\
\hline $\mathrm{C} \times \mathrm{V}$ & NS & NS & NS & NS \\
\hline $\mathrm{A} \times \mathrm{V}$ & $0.024 *$ & $0.021 *$ & NS & NS \\
\hline $\mathrm{C} \times \mathrm{A} \times \mathrm{V}$ & $0.034 *$ & NS & NS & $2.52 *$ \\
\hline
\end{tabular}

Table 6: Effects of $\mathrm{CO}_{2}$ elevation and AMF inoculation on percent mycorrhizal colonization and AMF sporulation of soybean cultivars at 6 and 9 WAP (screen house experiment)

\begin{tabular}{lcccc}
\hline Treatments & \multicolumn{2}{c}{$\begin{array}{c}\text { Percent mycorrhizal } \\
\text { colonization (\%) }\end{array}$} & \multicolumn{2}{c}{ Spore count } \\
\cline { 2 - 5 } & 6 WAP & 9 WAP & 6 WAP & 9 WAP \\
\hline $\mathrm{CO}_{2}$ LEVEL (C) & & & & \\
Ambient & 36.9 & 50.6 & 41.5 & 53.4 \\
Elevated & 41.9 & 62.2 & 45.4 & 63.1 \\
LSD & $4.27 *$ & $2.81^{* *}$ & NS & $5.81^{* *}$ \\
AMF (A) & & & & \\
Inoculated & 48.0 & 68.9 & 50.5 & 65.0 \\
Uninoculated & 30.7 & 43.9 & 36.4 & 51.4 \\
LSD & $4.27 * *$ & $2.81 * *$ & $4.63 * *$ & $5.81^{* *}$ \\
Varieties (V) & & & & \\
TGx 1448-2E & 41.1 & 56.7 & 43.7 & 57.0 \\
TGx 1440-1E & 37.8 & 56.9 & 42.1 & 59.9 \\
TGx 1740-2F & 39.2 & 55.6 & 44.7 & 57.8 \\
LSD & NS & NS & NS & NS \\
C $\times$ A & $6.04 *$ & $3.97 *$ & NS & NS \\
C $\times$ V & NS & NS & NS & NS \\
A $\times$ V & NS & $4.87 *$ & NS & NS \\
C $\times$ A $\times$ V & NS & NS & NS & NS \\
\hline$*$ Significant at 5\% probability level; **Significant at $1 \%$ probability &
\end{tabular}

*Significant at $5 \%$ probability level; **Significant at $1 \%$ probability level, NS: Not significant, WAS: Weeks after planting

higher specific leaf area than inoculated at 9 WAP except at 6 WAP, when there were no significant differences between both. There were no significant varietal differences on specific leaf area, specific leaf weight and leaf area ratio at all periods of investigation (Table 4). The relative growth rate of soybean grown in $\mathrm{CO}_{2}$ enriched atmosphere was significantly higher than ambient at R2 (Table 5). Leaf relative growth rate of inoculated soybean was significantly higher than uninoculated at R2. Similar pattern was observed on the relative growth rate.

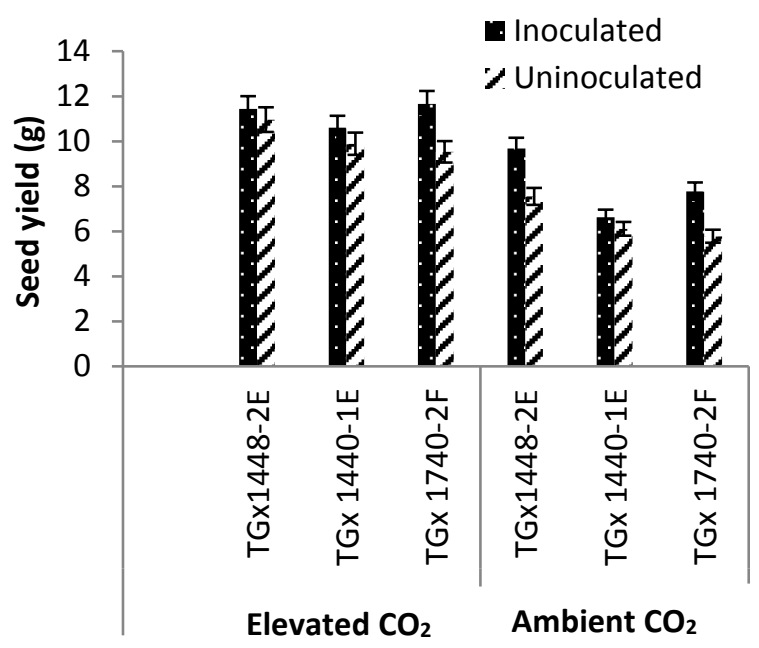

Figure 2: Interaction of $\mathrm{CO}_{2}$ enrichment $\times$ AMF inoculation $\times$ variety on seed yield, pot experiment. Bars in each column indicate standard error of mean $( \pm \mathrm{SE})$.

There were no significant differences among the varieties of soybean on leaf relative growth rate, relative growth rate and net assimilatory ratio at $\mathrm{R} 2$ (Table 5). Grain yield per plant was significantly higher in soybean grown in $\mathrm{CO}_{2}$ enriched atmosphere than ambient (Table 5). Significant varietal differences were observed on grain yield per plant. Grain yield per plant decrease was in the order TGx 1448-2E > TGx 1740-2F > TGx 1440-1E (Table 5). Significant $\mathrm{CO}_{2} \times \mathrm{AMF} \times$ Variety was observed on grain yield per plant (Fig. 2). Seed yield per plant of inoculated soybean was significantly higher than uninoculated at both $\mathrm{CO}_{2}$ enriched and ambient growth environments. Under $\mathrm{CO}_{2}$ enriched growth environment seed yield of inoculated soybean varieties was in a decreasing order of TGx 1740-2F > TGx 1448-2E > TGx 14401E. Under $\mathrm{CO}_{2}$ enriched growth environment seed yield per plant of uninoculated soybean varieties was in a decreasing order of TGx 1448-2E > TGx 14401E >TGx 1740-2F. Soybean sown at elevated $\mathrm{CO}_{2}$ concentration had significantly higher percentage mycorrhizal colonisation than ambient at all periods of investigation (Table 6). Similar pattern was observed on spore count at 9 WAP except at 6 WAP, where no significant differences were observed on spore count between soybean sown at elevated $\mathrm{CO}_{2}$ and those grown under ambient environment. At all period of investigation percentage AMF colonisation was significantly higher in inoculated soybean than un-inoculated. Similar pattern was observed on spore count at all sampling period. There were no significant varietal differences on percentage AMF colonisation and spore count at all investigation periods (Table 6). 
Sakariyawo, O.S., Adeyemi, O.N., Atayese, M.O., and Aderibigbe, S.G.

Table 7: Effects of $\mathrm{CO}_{2}$ enrichment and AMF inoculation on number of trifoliolate leaves and chlorophyll content of soybean cultivars at 3,6 and 9 WAP (field experiment)

\begin{tabular}{|c|c|c|c|c|c|c|}
\hline \multirow{2}{*}{ Treatments } & \multicolumn{3}{|c|}{ Number of trifoliolate Leaves } & \multicolumn{3}{|c|}{ Chlorophyll contemt } \\
\hline & 3 WAP & $6 \mathrm{WAP}$ & $9 \mathrm{WAP}$ & $3 \mathrm{WAP}$ & 6 WAP & $9 \mathrm{WAP}$ \\
\hline \multicolumn{7}{|l|}{$\mathrm{CO}_{2}$ level $(\mathrm{C})$} \\
\hline Ambient & 2.23 & 14.04 & 22.15 & 44.79 & 41.98 & 36.43 \\
\hline Elevated & 2.46 & 16.11 & 27.61 & 43.96 & 41.77 & 36.34 \\
\hline LSD & NS & $0.28 *$ & $0.38 *$ & NS & NS & NS \\
\hline \multicolumn{7}{|l|}{$\mathrm{AMF}(\mathrm{A})$} \\
\hline Inoculated & 2.34 & 16.44 & 25.29 & 45.32 & 41,92 & 36.89 \\
\hline Uninoculated & 2.35 & 13.71 & 24.47 & 43.43 & 41.83 & 35.88 \\
\hline LSD & NS & $0.28 *$ & NS & NS & NS & NS \\
\hline \multicolumn{7}{|c|}{ VARIETIES (V) } \\
\hline TGx 1448-2E & 2.08 & 13.30 & 25.24 & 44.44 & 42.86 & 36.52 \\
\hline TGx 1440-1E & 2.53 & 15.79 & 25.32 & 45.37 & 41.88 & 36.89 \\
\hline TGx 1740-2F & 2.43 & 16.12 & 24.08 & 43.32 & 40.89 & 35.73 \\
\hline LSD & NS & NS & NS & NS & NS & NS \\
\hline $\mathrm{C} \times \mathrm{A}$ & NS & $0.39 *$ & NS & NS & NS & NS \\
\hline $\mathrm{C} \times \mathrm{V}$ & NS & NS & NS & NS & NS & NS \\
\hline$A \times V$ & NS & NS & NS & NS & NS & NS \\
\hline $\mathrm{C} \times \mathrm{A} \times \mathrm{V}$ & NS & NS & NS & NS & NS & NS \\
\hline
\end{tabular}

Table 8: Effects of $\mathrm{CO}_{2}$ enrichment and AMF inoculation on leaf area and leaf area index of soybean cultivars at 3,6 and 9 WAP in 2015 (field experiment)

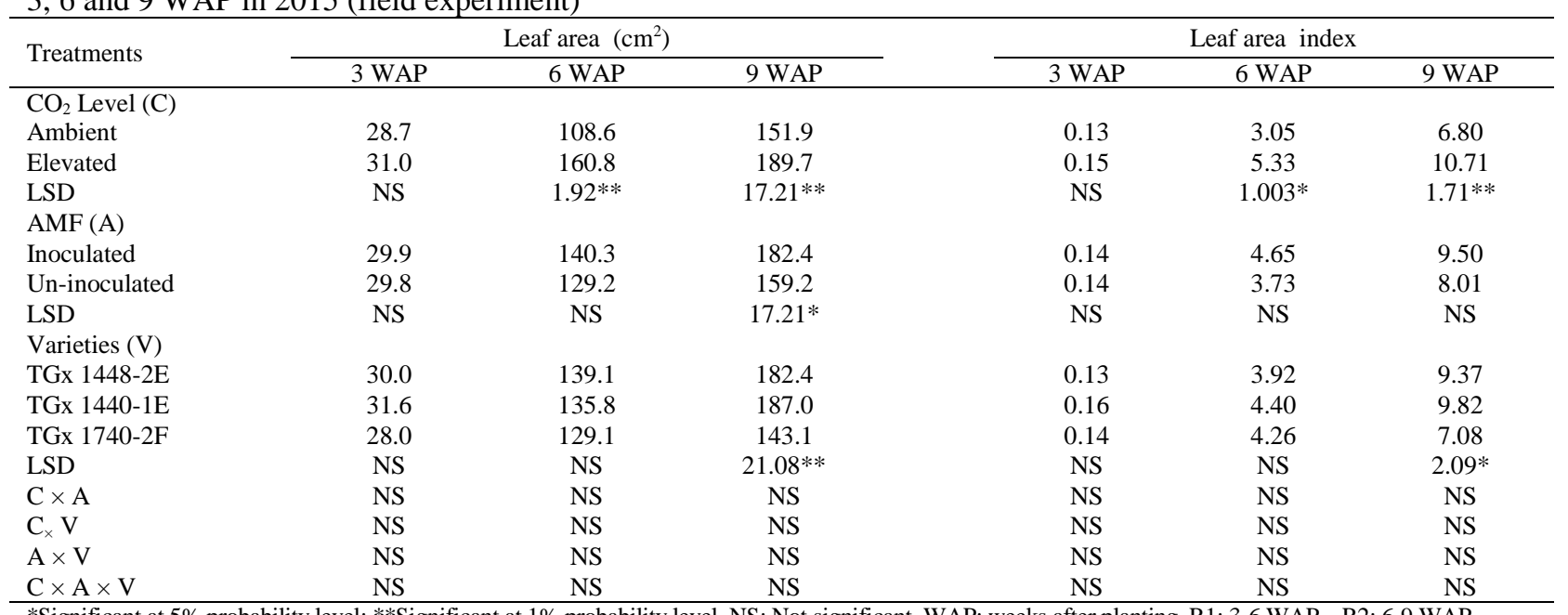

*Significant at 5\% probability level; **Significant at 1\% probability level, NS: Not significant, WAP: weeks after planting, R1: 3-6 WAP, R2: 6-9 WAP

Table 9: Effects of $\mathrm{CO}_{2}$ enrichment and AMF inoculation on leaf weight ratio and stem weight ratio of soybean cultivars at 3, 6 and 9 WAP in 2015 (field experiment)

\begin{tabular}{|c|c|c|c|c|c|c|}
\hline \multirow{2}{*}{ Treatments } & \multicolumn{3}{|c|}{ Leaf weight ratio } & \multicolumn{3}{|c|}{ Stem weight ratio } \\
\hline & $3 \mathrm{WAP}$ & $6 \mathrm{WAP}$ & $9 \mathrm{WAP}$ & $3 \mathrm{WAP}$ & $6 \mathrm{WAP}$ & $9 \mathrm{WAP}$ \\
\hline \multicolumn{7}{|l|}{$\mathrm{CO}_{2}$ level $(\mathrm{C})$} \\
\hline Ambient & 0.64 & 0.73 & 0.72 & 0.36 & 0.27 & 0.28 \\
\hline Elevated & 0.63 & 0.72 & 0.70 & 0.37 & 0.28 & 0.30 \\
\hline LSD & NS & NS & NS & NS & NS & NS \\
\hline \multicolumn{7}{|l|}{$\operatorname{AMF}(\mathrm{A})$} \\
\hline Inoculated & 0.65 & 0.73 & 0.75 & 0.35 & 0.27 & 0.25 \\
\hline Un-inoculated & 0.63 & 0.72 & 0.67 & 0.38 & 0.28 & 0.33 \\
\hline LSD & NS & NS & $0.06^{*}$ & NS & NS & $0.06^{*}$ \\
\hline \multicolumn{7}{|l|}{ Varieties (V) } \\
\hline TGx 1448-2E & 0.63 & 0.72 & 0.72 & 0.37 & 0.28 & 0.28 \\
\hline TGx 1440-1E & 0.65 & 0.73 & 0.74 & 0.35 & 0.27 & 0.26 \\
\hline TGx 1740-2F & 0.62 & 0.73 & 0.68 & 0.38 & 0.27 & 0.32 \\
\hline LSD & NS & NS & NS & NS & NS & NS \\
\hline $\mathrm{C} \times \mathrm{A}$ & NS & NS & NS & NS & NS & NS \\
\hline $\mathrm{C}_{\times} \mathrm{V}$ & NS & NS & NS & NS & NS & NS \\
\hline $\mathrm{A} \times \mathrm{V}$ & NS & NS & NS & NS & NS & NS \\
\hline $\mathrm{C} \times \mathrm{A} \times \mathrm{V}$ & NS & NS & NS & NS & NS & NS \\
\hline
\end{tabular}

*Significant at $5 \%$ probability level; **Significant at $1 \%$ probability level, NS: Not significant, WAP: weeks after planting 


\section{Field experiment}

The response of the number of trifoliate leaves and leaf area of soybean to enriched $\mathrm{CO}_{2}$ at 6 and 9 WAP followed similar pattern as was observed in the screen house trial (Tables 7 and 8). Inoculated soybean had significantly higher number of trifoliate leaves at 6 WAP than uninoculated. At 9 WAP similar pattern was observed on leaf area (Table 8). Significant varietal differences were observed on leaf area at 9 WAP. Increase in leaf area among the varieties was in the order TGx 1440-1E > TGx 14482E > TGx 1740-2F. Similar pattern was observed on leaf area index at 9 WAP (Table 8). At 9 WAP leaf weight ratio was more in inoculated than uninoculated (Table 9). Contrarily, stem weight ratio was more in un-inoculated soybean than inoculated at 9 WAP. Above ground dry biomass was significantly higher in soybean exposed to elevated $\mathrm{CO}_{2}$ than ambient atmospheric condition at all period of investigation except at 3 WAP (Table 10). Uninoculated soybean had significantly more above ground dry biomass than inoculated at 9 WAP; however at harvest maturity a reverse pattern was observed. There were no significant varietal differences on above ground dry biomass at all periods of investigation (Table 10). Enrichment of the growth environment had no significant effect on leaf area ratio at all periods of investigation except on the 9 WAP. It was observed that soybean sown at elevated $\mathrm{CO}_{2}$ had significantly higher leaf area ratio than those sown in the ambient $\mathrm{CO}_{2}$ (Table 11). At all periods of investigations, leaf relative growth rate, relative growth rate and net assimilatory rate were significantly higher in soybean grown in $\mathrm{CO}_{2}$ enriched environment that those in ambient $\mathrm{CO}_{2}$ concentration except leaf relative growth rate at R2 (Table 12). There were no significant differences on leaf relative growth rate of soybean grown at elevated and ambient $\mathrm{CO}_{2}$ concentration at R2 (Table 12). Grain yield was
Table 10: Effects of $\mathrm{CO}_{2}$ enrichment and AMF inoculation on aboveground dry biomass of Soybean cultivars at 3, 6, 9 WAP and harvest maturity in 2015 (field experiment)

\begin{tabular}{|c|c|c|c|c|}
\hline \multirow{2}{*}{ Treatments } & \multicolumn{3}{|c|}{ Aboveground dry biomass $\left(\mathrm{g}\right.$ plant $\left.^{-1}\right)$} & \multirow[b]{2}{*}{$\begin{array}{l}\text { Harvest } \\
\text { maturity }\end{array}$} \\
\hline & 3 WAP & $6 \mathrm{WAP}$ & 9 WAP & \\
\hline \multicolumn{5}{|l|}{$\mathrm{CO}_{2}$ level $(\mathrm{C})$} \\
\hline Ambient & 0.25 & 2.39 & 7.03 & 26.8 \\
\hline Elevated & 0.24 & 2.99 & 11.77 & 40.3 \\
\hline LSD & NS & $0.56^{*}$ & $2.27 * *$ & $5.28 *$ \\
\hline \multicolumn{5}{|l|}{$\operatorname{AMF}(\mathrm{A})$} \\
\hline Inoculated & 0.23 & 2.67 & 8.18 & 38.4 \\
\hline Un-inoculated & 0.25 & 2.71 & 10.62 & 28.7 \\
\hline LSD & NS & NS & $2.27 *$ & $5.28 * *$ \\
\hline \multicolumn{5}{|l|}{ Varieties (V) } \\
\hline TGx 1448-2E & 0.25 & 2.51 & 9.06 & 33.8 \\
\hline TGx 1440-1E & 0.24 & 2.76 & 9.53 & 34.7 \\
\hline TGx 1740-2F & 0.24 & 2.80 & 9.61 & 32.1 \\
\hline LSD & NS & NS & NS & NS \\
\hline $\mathrm{C} \times \mathrm{A}$ & NS & NS & NS & NS \\
\hline $\mathrm{C} \times \mathrm{V}$ & NS & NS & NS & NS \\
\hline $\mathrm{A} \times \mathrm{V}$ & NS & NS & NS & NS \\
\hline $\mathrm{C} \times \mathrm{A} \times \mathrm{V}$ & NS & NS & NS & NS \\
\hline
\end{tabular}

Significant at $5 \%$ probability level; ** Significance at $1 \%$ probability level, NS: Not significant, WAP: Weeks after planting

significantly higher in soybean grown at elevated $\mathrm{CO}_{2}$ than those at ambient $\mathrm{CO}_{2}$ concentration. At R2 leaf relative growth rate and relative growth rate was significantly higher in inoculated soybean than uninoculated. Inoculated soybean had significantly higher grain yield than uninoculated. There were no significant differences with respect to the aforestated leaf morphological characters and grain yield among the soybean varieties. Significant $\mathrm{CO}_{2} \times \mathrm{AMF} \times$ Variety was observed on the grain yield per hectare (Fig. 3). Inoculated soybean had significantly higher grain yield per hectare for all soybean varieties at both elevated and ambient $\mathrm{CO}_{2}$ concentration. The order of decrease in grain yield for soybean varieties inoculated at elevated $\mathrm{CO}_{2}$ was TGx $1740-2 \mathrm{~F}>\mathrm{TGx}$ 1448-2E > TGx 1440-1E. The order of decrease in grain yield of uninoculated soybean grown at elevated

Table 11: Effects of $\mathrm{CO}_{2}$ enrichment and AMF inoculation on specific leaf area, specific leaf weight and leaf area ratio of soybean cultivars at 3,6 and 9 WAP in 2015 (field experiment)

\begin{tabular}{|c|c|c|c|c|c|c|c|c|c|}
\hline \multirow[b]{2}{*}{ Treatments } & \multicolumn{3}{|c|}{ Specific leaf area $\left(\mathrm{cm}^{2} \mathrm{~g}^{-1}\right)$} & \multicolumn{3}{|c|}{ Specific leaf weight $\left(\mathrm{g} \mathrm{cm}^{-2}\right)$} & \multicolumn{3}{|c|}{ Leaf area ratio } \\
\hline & $3 \mathrm{WAS}$ & 6 WAS & $9 \mathrm{WAS}$ & $3 \mathrm{WAS}$ & 6 WAS & 9 WAS & $3 \mathrm{WAS}$ & $6 \mathrm{WAS}$ & 9 WAS \\
\hline \multicolumn{10}{|l|}{$\mathrm{CO}_{2}$ Level $(\mathrm{C})$} \\
\hline Ambient & 189.9 & 80.4 & 26.4 & 0.006 & 0.017 & 0.035 & 121.5 & 49.7 & 25.8 \\
\hline Elevated & 213.6 & 68.3 & 37.5 & 0.005 & 0.014 & 0.045 & 132.1 & 57.7 & 17.3 \\
\hline LSD & NS & NS & NS & NS & NS & NS & NS & NS & $6.1 * *$ \\
\hline \multicolumn{10}{|l|}{$\operatorname{AMF}(\mathrm{A})$} \\
\hline Inoculated & 208.0 & 78.9 & 26.8 & 0.005 & 0.015 & 0.043 & 132.6 & 57.7 & 20.1 \\
\hline Un-inoculated & 195.5 & 69.8 & 37.1 & 0.006 & 0.016 & 0.037 & 121.0 & 49.7 & 23.0 \\
\hline LSD & NS & NS & NS & NS & NS & NS & NS & NS & NS \\
\hline \multicolumn{10}{|l|}{ Varieties (V) } \\
\hline TGx 1448-2E & 200.9 & 86.5 & 35.9 & 0.005 & 0.014 & 0.035 & 125.2 & 62.3 & 25.0 \\
\hline TGx 1440-1E & 212.5 & 70.2 & 30.9 & 0.005 & 0.015 & 0.039 & 137.7 & 50.8 & 21.7 \\
\hline TGx $1740-2 \mathrm{~F}$ & 191.9 & 66.4 & 29.1 & 0.006 & 0.017 & 0.046 & 117.6 & 48.0 & 17.9 \\
\hline LSD & NS & NS & NS & NS & NS & NS & NS & NS & NS \\
\hline $\mathrm{C} \times \mathrm{A}$ & NS & NS & NS & NS & NS & NS & NS & NS & NS \\
\hline $\mathrm{C}_{\times} \mathrm{V}$ & NS & NS & NS & NS & NS & NS & NS & NS & NS \\
\hline $\mathrm{A} \times \mathrm{V}$ & NS & NS & NS & NS & NS & NS & NS & NS & NS \\
\hline $\mathrm{C} \times \mathrm{A} \times \mathrm{V}$ & NS & NS & NS & NS & NS & NS & NS & NS & NS \\
\hline
\end{tabular}

*Significant at $5 \%$ probability level; **Significant at $1 \%$ probability level, NS: Not significant, WAP: weeks after planting 
Table 12: Effects of $\mathrm{CO}_{2}$ enrichment and AMF Inoculation on relative leaf growth rate, relative growth rate and net assimilatory ratio of soybean cultivars (field experiment)

\begin{tabular}{|c|c|c|c|c|c|c|c|}
\hline \multirow[t]{2}{*}{ Treatments } & \multicolumn{2}{|c|}{$\begin{array}{l}\text { Leaf relative growth rate } \\
\qquad\left(\mathrm{g} \mathrm{g}^{-1} \mathrm{day}^{-1}\right)\end{array}$} & \multicolumn{2}{|c|}{$\begin{array}{l}\text { Relative growth rate } \\
\left(\mathrm{g} \mathrm{g}^{-1} \text { day }^{-1}\right)\end{array}$} & \multicolumn{2}{|c|}{ Net assimilatory ratio } & \multirow{2}{*}{$\begin{array}{l}\text { Grain yield } \\
\quad\left(\mathrm{t} \mathrm{ha}^{-1}\right)\end{array}$} \\
\hline & $\mathrm{R} 1$ & $\mathrm{R} 2$ & $\mathrm{R} 1$ & $\mathrm{R} 2$ & $\mathrm{R} 1$ & R2 & \\
\hline \multicolumn{8}{|l|}{$\mathrm{CO}_{2}$ Level (C) } \\
\hline Ambient & 0.112 & 0.049 & 0.106 & 0.049 & 0.152 & 0.068 & 1.97 \\
\hline Elevated & 0.126 & 0.062 & 0.119 & 0.065 & 0.174 & 0.092 & 3.52 \\
\hline LSD & $0.012 *$ & NS & $0.01 *$ & $0.012 *$ & $0.016^{* *}$ & $0.017 * *$ & $0.44 * *$ \\
\hline \multicolumn{8}{|l|}{$\operatorname{AMF}(\mathrm{A})$} \\
\hline Inoculated & 0.121 & 0.065 & 0.114 & 0.064 & 0.163 & 0.086 & 3.01 \\
\hline Un-inoculated & 0.118 & 0.046 & 0.111 & 0.051 & 0.162 & 0.074 & 2.48 \\
\hline LSD & NS & $0.014 *$ & NS & $0.012 *$ & NS & NS & $0.44 * *$ \\
\hline \multicolumn{8}{|l|}{ Varieties (V) } \\
\hline TGx 1448-2E & 0.114 & 0.058 & 0.108 & 0.058 & 0.156 & 0.080 & 2.95 \\
\hline TGx 1440-1E & 0.122 & 0.058 & 0.116 & 0.058 & 0.165 & 0.078 & 2.65 \\
\hline TGx 1740-2F & 0.122 & 0.050 & 0.114 & 0.055 & 0.166 & 0.081 & 2.64 \\
\hline LSD & NS & NS & NS & NS & NS & NS & NS \\
\hline $\mathrm{C} \times \mathrm{A}$ & NS & NS & NS & NS & NS & NS & $0.62 *$ \\
\hline $\mathrm{C}_{\times} \mathrm{V}$ & NS & NS & NS & NS & NS & NS & $0.77 *$ \\
\hline$\hat{A} \times \mathrm{V}$ & NS & NS & NS & NS & NS & NS & NS \\
\hline $\mathrm{C} \times \mathrm{A} \times \mathrm{V}$ & NS & NS & NS & NS & NS & NS & $1.08 * *$ \\
\hline
\end{tabular}

*Significant at 5\% probability level; **Significant at 1\% probability level, NS: Not significant, WAP: weeks after planting R1: 3-6 WAP, R2: 6-9 WAP

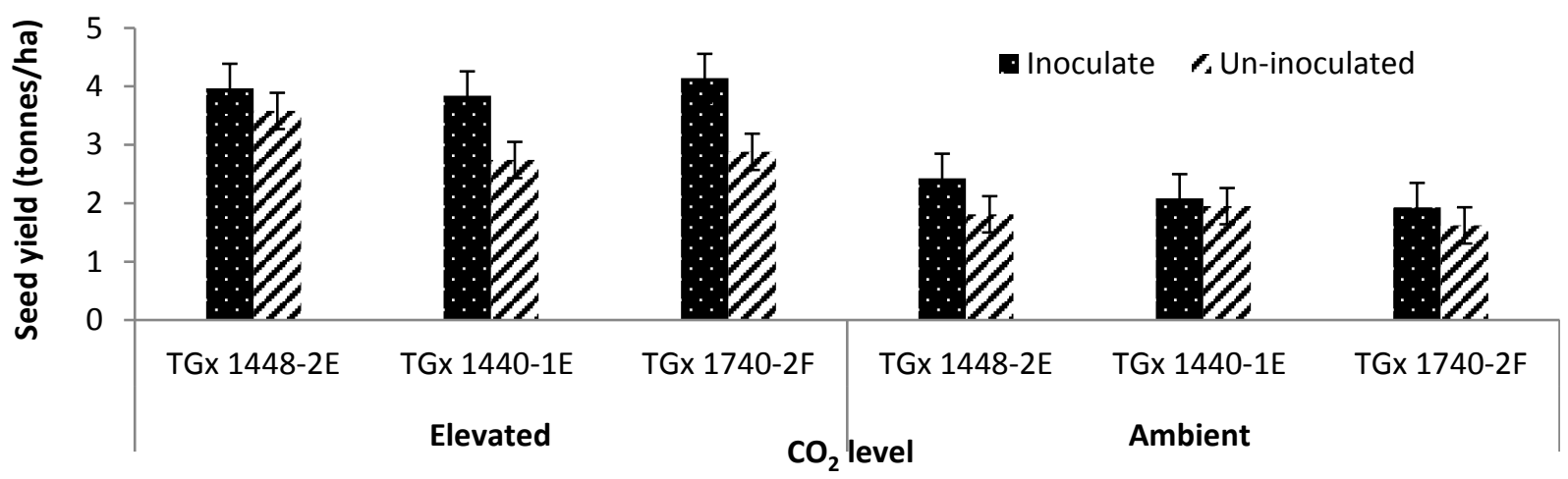

Figure 3: Interaction of $\mathrm{CO}_{2}$ elevation $\times \mathrm{AMF}$ inoculation $\times$ variety on seed yield $\mathrm{t} \mathrm{th}^{-1}$, tield experiment.

Bars in each column indicate standard error of mean $( \pm \mathrm{SE})$

$\mathrm{CO}_{2}$ was TGx 1448-2E > TGx 1740-2F > TGx 1440-

1E. At ambient $\mathrm{CO}_{2}$ concentration grain yield ha- ${ }^{-1}$ of inoculated soybean varieties decreased in the order TGx 1448-2E > TGx 1440-1E > TGx 1740-2F. At ambient $\mathrm{CO}_{2}$ concentration grain yield $\mathrm{ha}^{-1}$ of uninoculated soybean varieties decreased in the order TGx 1440-1E > TGx 1448-2E > TGx 1740-2F. Mycorrhizal colonisation was significantly higher in soybean grown at elevated $\mathrm{CO}_{2}$ than at ambient $\mathrm{CO}_{2}$ concentration at all periods of investigation except at $3 \mathrm{WAP}$, when there was no significant effect on this variable (Table 13). There was no significant effect of $\mathrm{CO}_{2}$ enrichment on the soil spore count at all periods of investigation except at $9 \mathrm{WAP}$. At $9 \mathrm{WAP}$ soybean crop grown at elevated $\mathrm{CO}_{2}$ concentration had significantly higher soil spore count than those grown at ambient $\mathrm{CO}_{2}$ concentration. Percentage AMF colonisation and soil spore count were significantly higher in inoculated soybean than uninoculated at all periods of investigation.

\section{DISCUSSION}

Increased number of trifoliate leaves and leaf area at 6 and 9 WAP in both trials under elevated $\mathrm{CO}_{2}$ in the growth environment could have suggested increased canopy closure with increased light capture to facilitate carbon assimilation. On the field at the canopy level increased assimilatory surface in $\mathrm{CO}_{2}$ enriched environment was facilitated by significantly higher leaf area index than soybean grown at ambient $\mathrm{CO}_{2}$ concentration. Ainsworth et al. (2002) reported similar response where she indicated that there was $39 \%$ and $13 \%$ increase in photosynthetic rate and leaf area of soybean respectively under elevated $\mathrm{CO}_{2}$ condition. The high carbon assimilatory process under elevated $\mathrm{CO}_{2}$ in the atmosphere could have supported increased relative growth rate especially at the earlier period of soybean growth. Rogers et al. (1984) had reported that there was a significant depression in the stimulating effect of elevated $\mathrm{CO}_{2}$ on growth parameters with time. In this investigation, 
Table 13: Effects of $\mathrm{CO}_{2}$ elevation and AMF inoculation on percent mycorrhizal colonization and AMF sporulation of soybean cultivars at 3,6 and 9 WAP (field experiment)

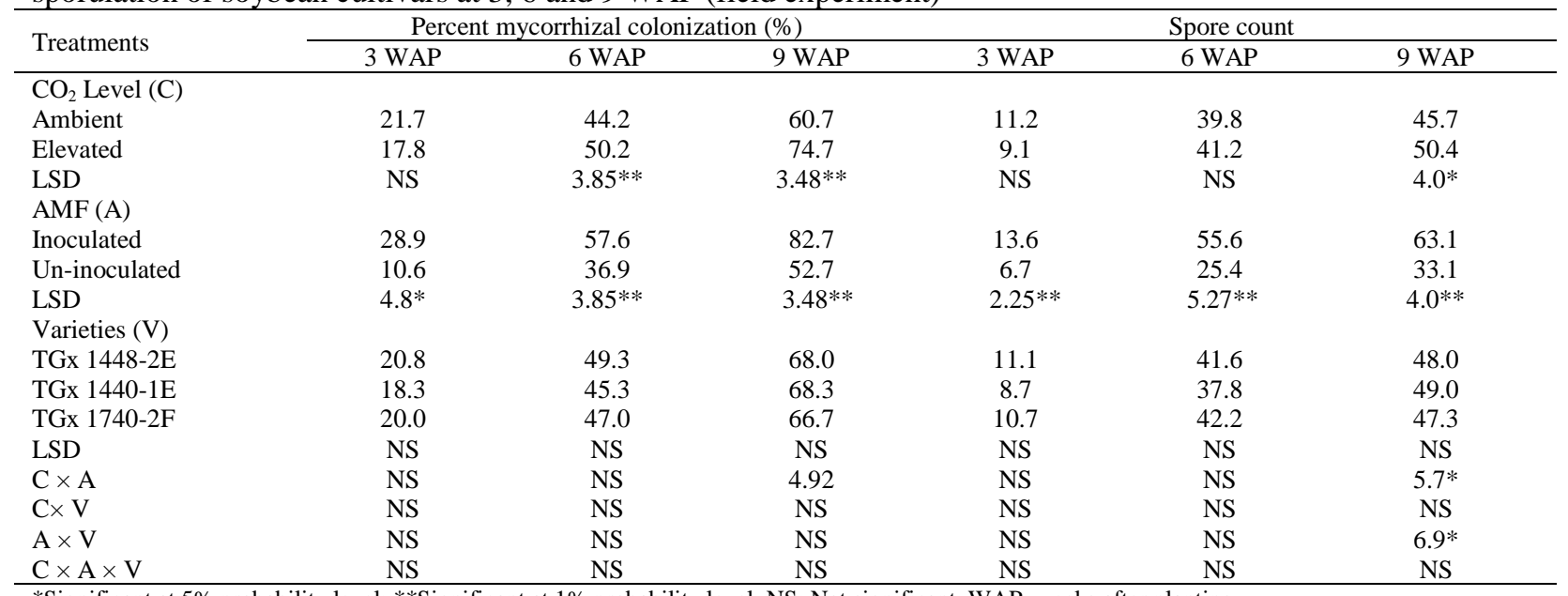

*Significant at $5 \%$ probability level; **Significant at $1 \%$ probability level, NS: Not significant, WAP: weeks after planting

this was supported by the significant increase in the speed of canopy development as evidence in significantly higher leaf relative growth rate on the field at $\mathrm{R} 1$ and $\mathrm{R} 2$ than soybean cultivated under ambient $\mathrm{CO}_{2}$ condition. This evidence was supported by the observation made by Cure et al. (1987). This response pattern was equally corroborated by Poorter (1993), where he indicated that among the C3 crops the faster their growth under elevated $\mathrm{CO}_{2}$ the higher the stimulating effect of $\mathrm{CO}_{2}$. On the field a converse pattern was observed on leaf area ratio with time under elevated $\mathrm{CO}_{2}$. Available literature had indicated that with increase in $\mathrm{CO}_{2}$ concentration in the atmosphere this could lead to the accumulation of starch (Makino and Mae, 1999) and increase in support tissue (Konings et al., 1989). Accumulation of starch in the chloroplast could facilitate feedback inhibition of carbon assimilation (Clough et al., 1981). The increase in the support tissue could lead to the mutual shading in the canopy and a down regulation of photosynthetic process (Konings et al., 1989). Increased above ground dry matter accumulation at 9 WAP in the screen house under elevated $\mathrm{CO}_{2}$ condition could have suggested a favourable carbon budgeting. Bunce and Caufield, (1991) reported a reduced respiratory rate per biomass in $\mathrm{CO}_{2}$ enriched environment in three herbaceous perennial species. This observation could have implied that more of carbon is incorporated into the formation of growth process than maintenance respiration. Finn and Brun (1982) and Cure et al. (1987) indicated that at elevated $\mathrm{CO}_{2}$ increased dry weight observed could be due to the accumulation of non structural carbohydrate. Increased relative growth rate in both trials in $\mathrm{CO}_{2}$ enriched environment especially at the early period of soybean development could have explained the significantly higher grain yield per plant observed in the screen house. This response pattern was equally validated on the field. However, on the field it could be suggested that the increased relative growth rate at $\mathrm{R} 1$ and $\mathrm{R} 2$ was as a result of increased net assimilatory rate in both periods with a significant depression in leaf area ratio at 9 WAP. Poorter (1993) suggested that photosynthetic rate and growth among different species under elevated $\mathrm{CO}_{2}$ could also be stimulated by the source:sink balance. In this investigation the presence of nitrogen fixing and AMF symbionts could have acted as metabolic sink. This hypothesis is supported by the significant increase in percentage AMF colonisation and spore count under elevated $\mathrm{CO}_{2}$ than soybean cultivated in ambient $\mathrm{CO}_{2}$ condition. In both trials increased spore count and percentage AMF colonisation could have acted as metabolic sink through the use of assimilates provided by the host soybean and the stimulation of photosynthetic rate through the supply of phosphorus and nitrogen from the symbionts. Supply of nitrogen is very important for the synthesis of light harvesting complex and the enzymes responsible for the normal functioning of photosynthesis. Cave et al. (1981) had earlier reported that leaves of Trifolium subterraneum experienced reduced chlorophyll $\mathrm{a}$ to $\mathrm{b}$ ratio per dry weight in $\mathrm{CO}_{2}$ enriched atmosphere. They further posited that under this condition accumulation of starch granules in the chloroplast together with the earlier mentioned observation could result in chlorosis. However, soybean as a legume can fix $\mathrm{N}$ biologically. This could have explained the non-significant effect of elevated $\mathrm{CO}_{2}$ on chlorophyll content observed in these trials. Phosphorus is a critical growth limiting factor in this agroecology. The availability of which could improve the performance of soybean through its effect on the supply of reducing agents to drive the dark reaction of photosynthesis. 
Similar interpretation could be adduced to the AMF effect on the assimilatory surface (leaf area and number of trifoliate leaves) of soybean under elevated $\mathrm{CO}_{2}$ in both trials. However, the increased assimilatory surface observed in AMF inoculated soybean could be ascribed to further changes in soybean morphology and their earlier development. This was evident in the increased leaf weight ratio, a reduction in the specific leaf area and rapid canopy development especially in the screen house trial. The field trial was established during the August break of the cropping season. The reduced rainfall at the time of sowing might have affected leaf expansion in the field. Water availability affects cellular elongation and growth (Boyer, 1988). The reduced specific leaf area might have increased chloroplast surface area and $\mathrm{CO}_{2}$ concentration in the intracellular spaces (Siebenkäs et al., 2015). Siebenkäs et al. (2015) also reported that increased intracellular $\mathrm{CO}_{2}$ could lead to a reduced Rubisco: $\mathrm{CO}_{2}$ ratio. Considering these response patterns of soybean to AMF inoculation, there might have been increased carboxylation and reduced oxygenation resulting in an increased photosynthetic process. This supposition could be inferred from the increased relative growth rate and dry matter accumulation observed in soybean inoculated with $\mathrm{AMF}$ in both trials. Inoculation of soybean with AMF would explain the higher spore count and AMF colonisation observed. Together with the presence of $\mathrm{N}$-fixing bacteria in soybean they could have acted as metabolic sink to stimulate photosynthesis, growth and grain yield in both trials.

Varietal differences on grain yield had soybean variety TGx 1448-2E with the highest performance in both trials though not significant on the field. The underlying growth mechanism indicated that it occupied intermediate position in leaf area index and the least significant leaf area at 9 WAP (field), probably a mechanism to forestall mutual shading in the canopy. This soybean variety showed a more adaptive performance as evidenced in both $\mathrm{CO}_{2}$ enriched environment without AMF inoculation and in ambient $\mathrm{CO}_{2}$ concentration when inoculated with AMF. It occupied an intermediate position when both factors were present or absent. However, soybean variety $\mathrm{TGx} 1740-2 \mathrm{~F}$ is more responsive to the combined effect of elevated $\mathrm{CO}_{2}$ and inoculation with $\mathrm{AMF}$ with a converse pattern when grown in ambient $\mathrm{CO}_{2}$ concentration in the absence of AMF inoculation. Meghvansi et al. (2008) reported genetic variability in AMF colonisation capacity of barley, grapevine, pepper and tomato. Similar conclusion was arrived at by Taiwo and Adegbite (2001) on selected soybean varieties in Nigeria. This suggests synergistic effect of the symbionts. However, Meghvansi et al. (2008) observed a selected synergistic relationship between the symbionts. Harris et al. (1985), who used one species of $\mathrm{AMF}$ in ambient $\mathrm{CO}_{2}$ concentration, posited that the combined effects of the symbionts in soybean reduced source:sink ratio with an increase in metabolic sink through increase in nodule activity in soybean. Other mechanisms behind the combined effects of the symbionts on the relative growth rate of soybean include increase in gross photosynthetic rate, increased leaf $\mathrm{P}$ concentration, increased specific leaf area with reduced leaf weight and increased starch mobilisation (Harris et al., 1985). Aranjuelo et al. (2014) reported that elevated $\mathrm{CO}_{2}$ regulated activity of the pathways for carbohydrate metabolism in $\mathrm{N}$ fixing pea plants. Specifically, there was an increase in starch and sucrose level in $\mathrm{CO}_{2}$ enriched environment. However, to ameliorate feedback inhibition of starch there was also increase in the activities of the protein responsible for the degradation of starch. Taken together the combined effects of $\mathrm{CO}_{2}$ enriched atmosphere with aforestated symbionts had not been fully explored in the literature. We hypothesize that for the $\mathrm{N}$-fixing legumes elevated $\mathrm{CO}_{2}$ in the atmosphere would increase the intracellular $\mathrm{CO}_{2}$ concentration, increase carboxylation and reduce oxygenation process. This would result in increased photosynthetic rate. Presence of metabolic sink through AMF colonisation and $\mathrm{N}$-fixing bacteria would supply $\mathrm{P}$ and $\mathrm{N}$ respectively to the legume. This metabolic stimulation would drive transportable form (sucrose) into the structures of the symbionts and lead to the degradation of starch to support this process at the same time ameliorate the feedback inhibition of starch. Our findings indicated that there could be varietal variation in this mechanism. The factors underlying this would require further studies.

\section{CONCLUSION}

Increased assimilatory surface observed in both trials at elevated $\mathrm{CO}_{2}$ could have increased the capacity of soybean varieties to intercept more light and increase gross photosynthetic rate. This could have explained increased growth rate in both trials, albeit with variation in the components of growth in both screen house and field trials. Presence of symbionts could have altered source:sink balance in preference for increased metabolic sink and stimulation of growth through photosynthesis. Growth stimulation under inoculation with AMF followed similar pattern with $\mathrm{CO}_{2}$ enrichment. The reduced specific leaf area under AMF inoculation could have altered chloroplast morphology and gas exchange properties positively for increased photosynthesis and growth. Soybean variety TGx $1448-2 \mathrm{E}$ is more adaptive to variation in AMF inoculation and $\mathrm{CO}_{2}$ enrichment in the atmosphere. Soybean TGx 1740-2F is more responsive to combined effect of AMF inoculation and N-fixing bacteria, while it less suitable in the absence of either of the symbionts or their combined absence. 


\section{ACKNOWLEDGMENTS}

The authors would like to appreciate Dr M.O. Dare of the Department of Soil Science and Land Management for his initial review of this manuscript.

\section{REFERENCES}

Ainsworth, E.A., Davey, P.A., Bernacchi, C.J., Dermody, O.C., Heaton, E.A., Moore, D.J. and Long, S.P. (2002). A meta-analysis of elevated $\left[\mathrm{CO}_{2}\right]$ effects on soybean (Glycine max) physiology, growth and yield. Glob. Chang. Biol., 8 (8), 695-709

Allison, L., Bollen, W.B., and Moodie, C.D. (1965). Total carbon. Methods of Soil Analysis. Part 2. Chemical and Microbiological Properties, (methodsofsoilanb), 1346-1366

Aranjuelo, I., Cabrerizo, P.M., Aparicio-Tejo, P.M. and ArreseIgor, C. (2014). Unravelling the mechanisms that improve photosynthetic performance of $\mathrm{N}$ 2-fixing pea plants exposed to elevated $\left[\mathrm{CO}_{2}\right]$. Environ. Exp. Bot., 99, 167-174

Augé, R.M. (2004). Arbuscular mycorrhizae and soil/plant water relations. Can. J. Soil Sci., 84(4), 373-381

Bouyoucos, G.J. (1962). Hydrometer method improved for making particle size analyses of soils. Agron. J., 54 (5), 464-465

Boyer, J.S. (1988). Cell enlargement and growth-induced water potentials. Physio. Plant, 73 (2), 311-316

Bray, R. and Kurtz, L. (1945). Determination of total, organic and available forms of phosphorus in soil. Soil Sci. , 59, 39-45

Bunce, J.A. and Caufield, F. (1991). Reduced respiratory carbon dioxide efflux during growth at elevated carbon dioxide in three herbaceous perennial species. Ann. Bot., 325-330

Cave, G., Tolley, L.C. and Strain, B.R. (1981). Effect of carbon dioxide enrichment on chlorophyll content, starch content and starch grain structure in Trifolium subterraneum leaves. Physio. Plant, 51 (2), 171-174

Clough, J.M., Peet, M.M. and Kramer, P.J. (1981). Effects of high atmospheric $\mathrm{CO}_{2}$ and sink size on rates of photosynthesis of a soybean cultivar. Plant Physiol., 67 (5), 1007-1010

Cure, J.D. and Acock, B. (1986). Crop responses to carbon dioxide doubling: a literature survey. Agric. For. Meteorol., 38 (1), 127-145

Cure, J.D., Rufty Jr, T.W. and Israel, D.W. (1987). Assimilate utilization in the leaf canopy and whole-plant growth of soybean during acclimation to elevated $\mathrm{CO}_{2}$. Bot. Gaz., $67-72$

Dornhoff, G.M. and Shibles, R.M. (1970). Varietal differences in net photosynthesis of soybean leaves. Crop Sci., 10 (1), $42-45$

Finn, G.A. and Brun, W.A. (1982). Effect of atmospheric $\mathrm{CO}_{2}$ enrichment on growth, nonstructural carbohydrate content, and root nodule activity in soybean. Plant Physiol., 69 (2), 327-331

Giovannetti, M. and Mosse, B. (1980). An evaluation of techniques for measuring vesicular arbuscular mycorrhizal infection in roots. New Phytol., 84 (3), 489-500

Harold, H., Keyser and Fudi, L. (1990). Potantial for increasing biological nitrogen fixation in soybean. In J. Ladha, T. George, and C. Bohloot (Eds.), Biological Nitrogen Fixation for Sustainable Agriculture (pp. 119135). Netherlands: Springer

Harris, D., Pacovsky, R.S. and Paul, E.A. (1985). Carbon economy of soybean-Rhizobium-Glomus associations. New Phytol., 101(3), 427-440

Hunt, R. (2012). Basic Growth Analysis: Plant Growth Analysis for Beginners. Springer Science and Business Media

Idris, A., Rasaki, K., Hodefe, O.J. and Hakeem, B. (2013). Consumption pattern of Ofada rice among civil servants in Abeokuta Metropolis of Ogun State, Nigeria. J. Biol. Agric. Healthcare, 3 (6), 106-112
Jackson, M. (1962). Chemical Soil Analysis. New Delhi: Prentice Hall of India Pvt, Ltd.

Kaschuk, G., Kuyper, T.W., Leffelaar, P.A., Hungria, M. and Giller, K.E. (2009). Are the rates of photosynthesis stimulated by the carbon sink strength of rhizobial and arbuscular mycorrhizal symbioses? Soil Biol. Biochem., 41 (6), 1233-1244

Konings, H., Koot, E. and Tijman-de Wolf, A. (1989). Growth characteristics, nutrient allocation and photosynthesis of Carex species from floating fens. Oecologia, 80 (1), 111-121

Leakey, A.D., Ainsworth, E.A., Bernacchi, C.J., Rogers, A., Long, S.P. and Ort, D.R. (2009). Elevated $\mathrm{CO}_{2}$ effects on plant carbon, nitrogen, and water relations: six important lessons from FACE. J. Exp. Bot., 60 (10), 2859-2876

Makino, A. and Mae, T. (1999). Photosynthesis and plant growth at elevated levels of $\mathrm{CO}_{2}$. Plant Cell Physiol., 40 (10), 999-1006

McLean, E. (1982). Soil pH and lime requirements. In: A. Page, R. Miller, and R. Keneey (Eds.), Methods of Soil Analysis (2nd Ed., pp. 199-223). Agronomy Society of America

Meghvansi, M.K., Prasad, K., Harwani, D. and Mahna, S.K. (2008). Response of soybean cultivars toward inoculation with three arbuscular mycorrhizal fungi and Bradyrhizobium japonicum in the alluvial soil. Eur. $J$. Soil Biol., 44 (3), 316-323

Murphy, J. and Riley, J.P. (1962). A Modified Single Solution Method for Determination of Phosphate in Natural Waters. Anal. Chim. Acta, 27, 31-36

Obalum, S.E., Igwe, C.A., Obi, M.E. and Wakatsuki, T. (2011). Water use and grain yield response of rainfed soybean to tillage-mulch practices in southeastern Nigeria. Sci. Agricola, 68 (5), 554-561

Phillips, J.M.and Hayman, D.S. (1970). Improved procedures for clearing roots and staining parasitic and vesiculararbuscular mycorrhizal fungi for rapid assessment of infection. T. Brit. Mycol. Soc., 55 (1), 158-I61

Poorter, H. (1993). Interspecific variation in the growth response of plants to an elevated ambient $\mathrm{CO}_{2}$ concentration. Vegetation, 104 (1), 77-97

Rogers, H.H., Cure, J.D., Thomas, J.F. and Smith, J.M. (1984). Influence of elevated $\mathrm{CO}_{2}$ on growth of soybean plants. Crop Sci., 24(2), 361-366

Saitoh, Y., Hattori, J., Chinone, S., Nihei, N., Tsuda, Y., Kurahashi, H. and Kobayashi, M. (2004). Yeastgenerated $\mathrm{CO}_{2}$ as a convenient source of carbon dioxide for adult mosquito sampling. J. Am. Mosq. Control Asso., 20 (3), 261-264

Siebenkäs, A., Schumacher, J. and Roscher, C. (2015). Phenotypic plasticity to light and nutrient availability alters functional trait ranking across eight perennial grassland species. AoB Plants, 7 , plv029

Smith, S. and Read, D. (2008). Mycorrhizal Symbiosis, (3rd edition). Amsterdam; Boston: Academic Press

Taiwo, L. and Adegbite, A. (2001). Effect of arbuscular mycorrhiza and Brydyrhizobium inoculation on growth, $\mathrm{N} 2$ fixation and yield of promiscuously nodulating soybean (Glycine max). J. Agric. Res., 2, 110-118

Uzoh, I.M., Obalum, S.E. and Ene, J. (2015). Mineralization rate constants, half-lives and effects of two organic amendments on maize yield and carbon-nitrogen status of loamy Ultisol in Southeastern Nigeria. Agro-Sci., 14 (3), 35-40.

Wiersma, J.V. and Bailey, T.B. (1975). Estimation of leaflet, trifoliolate, and total leaf areas of soybeans. Agron. J., 67 (1), 26

Wu, Q.S. and Zou, Y.N. (2010). Beneficial roles of arbuscular mycorrhizas in citrus seedlings at temperature stress. Sci. Hortic., 125 (3), 289-293 